\title{
Javanese lunar calendar effect (Primbon) on abnormal return
}

\author{
Sidarta Hermin \& Putu Anom Mahadwartha \\ University of Surabaya, Surabaya, Indonesia
}

\begin{abstract}
The purpose of this study is to examine Javanese lunar calendar (Primbon) effect to abnormal return on Indonesian Stock Market. Type of this study is conclusive descriptive using intraday trading data. The research observed and tested cultural phenomena called Primbon as a calendar effect on abnormal return. Studies of cultural event, Ramadhan effect. This research examined other issues which is a belief of traditional calendar called Primbon among Javanese in Indonesia. This study uses event study methodology to observe abnormal return of stocks recommended by Primbon that grouping into defensive stock called "rahayu" and aggressive stock called big luck (rezeki besar) on certain time in a day. Abnormal return from groups of stock recommended by Primbon only presented on Monday aggressive stocks group from 09.00 to 11.00. Thus it can be concluded that the recommendations of Primbon only partially affect the abnormal return on the Indonesia Stock Exchange.
\end{abstract}

Keywords: Javanese lunar calendar (Primbon), stock market, abnormal return.

\section{INTRODUCTION}

Burton \& Shah (2013) state that prices are a sign of incorrect information and resources are allocated inefficiently. There are two important cores of human behavior that are affective and cognitive. Man as a creature with a mind and free will sometimes think irrationally in making investment decisions done so that the assumption of efficient market much denied through many market anomaly research. Zhang et al. (2016) found an anomaly of day of the week effect in 25 countries: there were anomalies on Monday in stock markets in Argentina, Poland, Italy and Singapore; there are anomalies on Wednesday in stock markets in Mexico, Indonesia, Germany, Switzerland, Australia, Japan and New Zealand; there are anomalies on Thursday in the stock market in the Czech Republic and the Philippines; there are anomalies on Friday in stock markets in Brazil, Chile, Russia, Turkey, India, Malaysia, Spain and Hong Kong.

Malini \& Jais (2014) found that there is an anomalous January effect on shari'ah stocks in Malaysia, December effect on shari'ah stock in Indonesia, and February effect is stronger than January effect on shari'ah stock in Malaysia, and holiday effect which is only significant in shariah stocks in Malay- sia. Based on research Jaisinghani (2016) found that there is strong positive support to the September effect on the stock market in India. Haggard and Witte (2010) found significant results of Halloween effect in America in the period 1954-2008. Research conducted by Oprean \& Tanasescu (2014) found that stock trading conducted in the market was influenced by irrational investor behavior in Rome and Brazil. On the Roma market pessimistic investors are affecting trading volumes while Brazil is optimistic that investors affect market activity in the largest size. Another study of capital market anomalies is the calendar in Islam. Seyyed et al. (2005) in his research on Ramadan Effect also found a significant decline in volatility, implying a change in predictable price risk. Akrami et al. (2012) found there was a significant relationship between Ramadhan month and abnormal return of shares in Tehran Stock Exchange.

In fact, it is possible for investors to take action based on superstitions and common beliefs. It has also been proposed by Robiyanto \& Puryandani (2015) which states that cultural and superstitious considerations may influence the process of behavior formation in financial markets as an expression of social psychology. Another study that finds seasonal anomalies in the stock market is the lunar calendar 
effect. Wu (2013) found significant linkages between cultural holidays such as the Chinese New Year with abnormal returns in Asian stock markets, and cultural influences explaining holiday effects on Asian stock markets. Boubaker, et al. (2015) showed that overreaction occurred in specific event such as cultural and non-economic event. Brown et al. (2002) found the influence of cultural factors on investor behavior in Hong Kong and Taiwan stock markets. According to Robiyanto \& Puryandani (2015) there is a native culture in Indonesia that is similar to Oriental culture. The Java lunar calendar system has a close similarity to the Chinese lunar calendar for example, the Javanese people consider Wage Thursday (Kamis Wage) and Kliwon Friday (Jum'at Kliwon) to be a very special day compared to others based on their sacred characteristics. However, the study concluded that there was no significant impact on Kamis Wage and Jum'at Kliwon.

Research on the effects of Java calendar by Robiyanto \& Puryandani (2015) on Kamis Wage and Jum'at Kliwon no significant effect on abnormal return, so researchers interested to examine about the effects of primbon with a different approach that is with intraday trading approach where in a certain day there are times where there is a period of great sustenance, small sustenance, and safe (rahayu) (AlBuary 1984). This study classifies shares into aggressive and defensive stocks to test for abnormal returns based on predictions recommended by the primbon.

The great sustenance describes the large revenues or profits of stock trading so that aggressive stocks are used at a time of great sustenance as they represent opportunities for great profits where great profit opportunities also mean a great risk. While the small sustenance means the opportunity to get a small sustenance so that is expected at the time of small fortune the defensive and aggressive shares experienced a negative abnormal return.

Statman (2008) concludes that the collective set of people's experiences of the same culture will influence their cognitive and emotional approach to investing. According to Robiyanto \& Puryandani (2015), every different culture tends to have its own superstitions. For example, the number Thirteen is an unlucky number and Friday Thirteenth is a bad day for the people of many countries with JudeoChristian beliefs. Meanwhile, Oriental society often assumes that number four is an unlucky number because when read, the pronunciation indicates the meaning of "dead." The number eight is a lucky number because the pronunciation indicates the meaning of "luck". Beliefs about luck and misfortune are still widely embraced by various cultures, especially in the Asian continent. The beliefs about myths that circulate widely in a society whose folks cannot be proven make society irrational so it can also influence investment decisions.

This study uses dating method according to AlBuary (1984). Below is a hint about the right time or suitable to seek sustenance:

a. Sunday, the great sustenance from morning until noon, while from midday until evening small fortune.

b. Monday, the great sustenance from midday until evening (asar) and morning until noon little sustenance.

c. Tuesdays, great sustenance from morning until asar, while rahayu from noon until asar arrived.

d. Wednesday, small sustenance from morning until noon, rahayu when asar, and the great sustenance from sunset.

e. Thursdays, great sustenance when by noon, $r a-$ hayu in the morning. Little sustenance when the sun is in the middle and rahayu as the sun inclines to asar.

f. Friday, small fortune from early morning until late afternoon, rahayu from the sun leaning to the west to enter asar time.

g. Saturdays, great sustenance when the sun is leaning to the west, while starting in the morning until the middle of the day is a small sustenance.

\section{RESEARCH METHODS}

\subsection{Variable}

This research uses abnormal return variable which is difference between actual return (return earned significantly from stock price change) with expected return (expected return by investor obtained by using Single Index Model) on intraday trade according to time calculation of primbon. Here is the formula of the abnormal return:

$A R_{i t}=R_{i t}-E\left(R_{i t}\right)$

$A R_{i t}=$ abnormal rate of return stock $i$ on $t$

$R_{i t}=$ actual rate of return stock $i$ on $t$

$E\left(R_{i t}\right)=$ expected return stock $i$ on estimated period of $t$

$R_{i t}=\frac{P_{i t}-P_{i t-1}}{P_{i t-1}}$

$P_{i t}=$ stock price $i$ on period of $t$

$P_{i t-1}=$ stock price $i$ on period of $t-1$

$E\left(R_{i t}\right)=\alpha_{i}+\beta_{i} R_{m t}$

$\mathrm{E}(\mathrm{Rit})=$ expected return stock $\mathrm{i}$ on estimated period of $t$

$\alpha_{i}=$ constant of single index

$\beta_{i}=$ market risk

$R_{m t}=$ market rate of return

This study uses secondary data obtained from the yahoo finance website in the form of historical data 
adjusted closing price included in the LQ45 Index period of February 2017 - July 2017. Historical data used from January 2016 to December 2016 to get individual beta stock and return market composite index. Intraday trading data is obtained from securities companies.

The shares are then grouped into aggressive stocks that contain shares with $\beta>1$ and defensive shares that contain shares with $\beta<1$. There are 20 stocks in the aggressive or $\beta>1$ and 25 Defensive or $\beta<1$ groups.

This study used one-sample t-test parametric statistics to test whether there were abnormal returns during the event window, and independent sample ttest to test the difference of abnormal return between the two sample groups.

$\underline{\text { Table 1. Abnormal return of Aggressive and Defensive stock }}$

\begin{tabular}{cccc}
\hline \multicolumn{1}{c}{ Days } & Time & Aggressive & Defensive \\
\hline \multirow{2}{*}{ Monday } & $09.00-11.00$ & Negative & Negative \\
& $11.00-16.00$ & Positive & - \\
\hline \multirow{2}{*}{ Tuesday } & $09.00-11.00$ & Positive & - \\
& $11.00-16.00$ & - & Positive \\
\hline \multirow{2}{*}{ Wednesday } & $09.00-11.00$ & Negative & Negative \\
& $11.00-16.00$ & - & Positive \\
\hline \multirow{4}{*}{ Thursday } & $09.00-10.00$ & - & Positive \\
& $10.00-11.00$ & Positive & - \\
& $11.00-14.00$ & Negative & Negative \\
\multirow{2}{*}{ Friday } & $14.00-15.00$ & - & Positive \\
\hline
\end{tabular}

\section{RESULT AND DISCUSSION}

Table 2. Summary of Result

\begin{tabular}{ccc}
\hline Hypothesis & Abnormal Rt & Sig \\
\hline 1 & Negative & Significant \\
2 & Negative & Insignificant \\
3 & Positif & Insignificant \\
4 & Positif & Insignificant \\
5 & Positif & Insignificant \\
6 & Negative & Insignificant \\
7 & Negative & Insignificant \\
8 & Positif & Insignificant \\
9 & Negative & Insignificant \\
10 & Positif & Significant \\
11 & Positif & Insignificant \\
12 & Negative & Insignificant \\
13 & Negative & Insignificant \\
14 & Negative & Insignificant \\
15 & Positif & Insignificant \\
\hline
\end{tabular}

This research discusses only hypotheses 1 and 10 that proved to be significant abnormal return during intraday trading.
H1: On Monday a negative abnormal return of aggressive stocks between 09:00 to 11:00.

Based on Hypothesis 1 test result, it can be concluded that there is negative abnormal return on aggregate stock group between 09.00-11.00 hours on Monday. This suggests that the Primbon prediction in predicting abnormal returns in aggregate stocks between 09.00-11.00 on Monday is proven. It also proves that the stock market on aggregate stocks between 09.00-11.00 hours on Monday is inefficient in weak form. In a weak form capital market, the price of a financial asset is unpredictable. The asset price moves randomly and unpredictably so that the investor cannot get the abnormal return, or in other words all participants in the market will only get normal return, but in this research stock price can be predicted by using Primbon reference, so it can be said that the capital market is inefficient based on test result on aggressive stock group between 09.0-11.00 hours. H10: On Thursday a positive abnormal return of defensive stock between 14:00 to 15:00

Based on hypothesis testing, it can be concluded that there is negative abnormal return. This finding is not in accordance with the hypothesis that there should be a positive abnormal return on defensive shares between the hours of 14:00 to $15: 00$ on Thursday. It can be concluded that there is influence other than Primbon that cause the abnormal return on defensive shares between the hours of 14:00 to 15:00 on Thursday.

The paired sample t-test test was performed on two stock groups that had significant results on one sample t-test. The results of this test indicate a significant level of significance of $10 \%$, meaning that there is a significant difference between the average abnormal return on aggressive stocks on Monday between the hours of 09:00 to 11:00 and Thursday for defensive shares between the hours of 14:00 to 15:00. The average abnormal return of aggressive stock on Monday between 09.00-11.00 hours is $0.45 \%$ and Thursday for defensive stock between $14.00-15.00$ hours is $-0.16 \%$. The average negative abnormal return in the Thursday group was smaller than Monday and the average difference between the two groups of stocks was $-0.29 \%$. The Paired test is also performed using bootstrapping, with the test results showing the consistency of the result that there is a difference between aggressive stocks on Monday between 09.00-11.00 hours and Thursday for defensive stocks between the hours of 14:00 to 15:00.

This test shows that there is a difference between aggressive stock abnormal returns on Monday between 09.00-11.00 hours and Thursday for defensive shares between the hours of 14:00 to 15:00. These results prove that stocks in the defensive class have a smaller negative abnormal return compared with the 
abnormal returns that occur in aggressive stocks. It also proves that the risk on aggressive stocks is greater than the risk on defensive stocks.

\section{CONCLUSION}

This study aims to prove empirically Primbon effect against abnormal return on Indonesia Stock Exchange LQ45 index by using intraday data. Based on Monday's test, only for aggressive shares between 09.00-11.00 hours and Thursday for defensive shares between the hours of 14:00 to 15:00 which results can be received in line with the recommendations of Primbon. Therefore, it can be concluded that the LQ45 index of the Indonesian stock market is not fully influenced by Primbon as a consideration in its investment decision.

This study found that on the classification of shares of rahayu which is the classification of defensive stocks, has a smaller risk of aggressive stock groups or rejeki besar. Defensive stock groups or rahayu have a smaller negative abnormal return compared to aggressive stock groups or rejeki besar.

This research suggests investors in Indonesia's stock market that have lower risk preference to buy defensive stock (beta less than 1) because the stock has lower risk while investor with higher risk preference can buy stocks belonging to the company aggressive shares because they have a higher risk but with higher income expectations as well.

\section{REFERENCES}

Akrami, H., Garkaz M., \& Mehrazin A. 2012. The effect of Ramadhan month on stocks abnormal return of the companies accepted in Tehran stock exchange, Economics and Finance Review 2(5): 45-51.

Al-Buary, I.S. 1984. Kumpulan Primbon Jawa Lengkap. Surabaya: Mahkota.

Boubaker, S., Farag, H., \& Nguyen, D. K. 2015. Short-term overreaction to specific events: Evidence from an emerging market. Research in international business and finance 35: 153-165.

Burton, E., \& Shah, S. 2013. Behavioral finance: understanding the social, cognitive, and economic debates. New Jersey: John Wiley \& Sons.

Brown P., Chua, P. \& Mitchell J. 2002, The Influence of Cultural Factors on Price Clustering: Evidence from AsiaPacific Stock Markets, Pacific-Basin Finance Journal 10: 307-332.

Haggard, K. S., \& Witte, H. D. 2010. The Halloween effect: Trick or treat? International Review of Financial Analysis 19(5): 379-387.

Jaisinghani, D. 2016. An empirical test of calendar anomalies for the Indian securities markets. South Asian Journal of Global Business Research 5(1): 53-84.
Malini, H., \& Jais, M. 2014. Month of the Year and PreHoliday Effects In Indonesia and Malaysia Shari'ah Compliance. Indonesian Capital Market Review 6(1): 38-48

Oprean, C., \& Tanasescu, C. 2014. Effects of Behavioural Finance on Emerging Capital Markets. Procedia Economics and Finance 15: 1710-1716.

Robiyanto, R., \& Puryandari, S. 2015. The Javanese Lunar Calendar's Effect on Indonesian Stock Returns. Gadjah Mada International Journal of Business 17(2): 125-137.

Seyyed, F. J., Abraham, A., \& Al-Hajiji, M. 2005. Seasonality in stock returns and volatility: The Ramadan effect. Research in International Business and Finance 19 (3): 374-383.

Statman, M. 2008. Countries and Cultural in Behavior Finance. CFA Institute, September: 38-44

Wu, C. 2013. The Chinese New Year Holiday Effect: Evidence from Chinese ADRs. Investment Management and Financial Innovation 10(2): 8-14

Zhang, J., Lai, Y., \& Lin, J. 2016. The day-of-the-Week effects of stock markets in different countries, Finance Research Letters 20: 47-62. 